\title{
Editorial
}

\section{Un pingüino muerto en el litoral central: El arte de la sospecha, la búsqueda de la unidad diagnóstica, la virtud de sermente abierta, de no perder la capacidad de asombro y de tener respeto a lascanas.}

'Hace algún tiempo atrás uno de mis hijos, mientras caminábamos por la playa, se impresionó al encontrar un pingüino muerto a la orilla del mar. Al momento de observarlo se percibía en sus gestos, en su actuar, el asombro y tristeza que tal descubrimiento le producían. Seguida dicha reacción, el paso siguiente fue demandar explicación del fenómeno, como era posible y si era prevenible. Sus numerosas preguntas pusieron a prueba mi conocimiento y me hicieron darme cuenta que no todo tiene una respuesta inmediata o una explicación fácil a la cual atribuir la situación'. Por suerte para mi, una pelota distraída se cruzó por su mirada y ello evito el bochorno de responder innumerables no sé.

Esta pequeña historia ilustra el concepto que brevemente quiero abordar en esta editorial y que trata sobre la importancia de reconocer que siempre habrán situaciones médicas que nos sorprenderán y donde la convergencia de expertos puede eventualmente ofrecer explicaciones y soluciones a situaciones inicialmente consideradas inhabituales, muchas de ellas originadas en situaciones fuera del ámbito de nuestro 'expertise'. Escenarios donde además la medicina basada en la evidencia carece de información o nunca podrá ofrecernos una respuesta generalizable o aplicable a tal escenario infrecuente pero plausible de tocarnos vivir.

Es claro de la historia que encontrar un pingüino muerto en la playa no es algo frecuente de ver $y$ menos de explicar a un niño pequeño. Sin embargo, ello no resultará inhabitual o inexplicable si se conoce de los ciclos vitales de la especie, si se sabe que dicha especie habita, migra y que puede ser visitante de la zona en cuestión y de que los pingüinos son presa de depredadores, de los accidentes de la naturaleza y que su vida también se puede extinguir producto de la intervención humana. Sin ser experto en la materia, el haber vivido una situación similar en el pasado permitiría entender que tal situación es posible y por ende ofrecer una explicación más expedita al niño inquisitivo. Situaciones como estas dan sentido a la voz de la experiencia y la relevancia que puede tener el consultar 'al médico con más canas en sus sienes' que tratar de buscar la respuesta rápida en la revisión sistemática que esté disponible en Up to Date.

Como muchos, en mi etapa más joven, sentí que todo debía tener una explicación razonable, que mis ocurrencias eran 'siempre' novedosas y que la mayoría de las situaciones donde existía 'error médico' probablemente se originaban en el desconocimiento o en el no mantenerse actualizado por parte del clínico. Así también que todas las acciones médicas se debían sustentar en estudios clínicos de buen diseño y validados en diferentes escenarios para justificar su aplicabilidad. Sin embargo, hay muchas situaciones clínicas donde la respuesta requerirá del consejo sabio del más viejo, de la convergencia de otros expertos que miran el caso desde una perspectiva diferente y de pensar que existen explicaciones las cuales pueden originarse en algo que sin dudas nos asombrará pero que ya no será desconocido una próxima vez.

En este número en particular, se presentan al menos 4 casos que desafían nuestro conocimiento y que revitalizan la capacidad de asombro. Un caso de endometriosis extra ginecológica asociado a carcinoma de células claras, el caso de dolor abdominal puerperal originado en un tumor del saco vitelino, un raro caso de leiomiosarcoma diagnosticado durante el embarazo y un cáncer epitelial de ovario de presentación atípica en contexto de estado portador de mutación de BRCA. Así 
también una revisión que pone en el horizonte una temática poco considerada por los obstetras y que merece atención, la fatiga del postparto.

Muchos críticos cuestionan la relevancia y utilidad de reportar casos. Sin embargo, la rareza de sus escenarios, su impredecibilidad y evolución, las estrategias usadas para arribar al diagnóstico o alcanzar la unidad diagnóstica y la inteligencia convergente de las mentes que conforman el equipo médico para encontrar la solución, todas ellas son razones para valorar su publicación. De la lectura de los 4 casos queda claro, que la convergencia de expertos, con distintos talentos y conocimiento, muchos de ellos con canas en sus sienes, logra efectos virtuosos en el enfermo. Sin dudas, cada vez que se publica uno de estos casos, tanto el autor como el lector hacen manifiesta su capacidad de asombro y dan reconocimiento al esfuerzo conjunto que permitió diagnosticar y tratar un caso complejo e inhabitual. Más importante aún, en estos casos queda reflejado el análisis crítico a nuestras propias acciones y el darnos cuenta que el aprendizaje se hace más sólido cuando la teoría se conjuga con la práctica y las vivencias.
Con los años y en la medida que transito hacia el grupo con más canas, afortunadamente la madurez me alcanza y me hace mirar en perspectiva $y$ replantear acciones pretéritas que siempre consideré correctas o justificadas. Así también, la trayectoria y lugar de trabajo escogidos me han permitido descubrir la relevancia de los distintos pensamientos, ya sea jóvenes, viejos, inquisitivos, cuestionadores o eventualmente inquisidores. Más importante aún, el darme cuenta que el índice de sospecha aumenta exponencialmente cuando se conjuga el conocimiento con las vivencias.... la evidencia con la experiencia. Cuando se prioriza desde lo frecuente a lo infrecuente. Cuando la inexperiencia da cabida a la creatividad, y cuando se considera que todo es posible y que no siempre tendrá la respuesta sino que ella saldrá de la convergencia de distintos talentos al servicio del conocimiento y del bien común.

\section{Dr. Mauricio Cuello Fredes}

\section{Profesor Titular Obstetricia y Ginecología}

Editor en Jefe Revista SOCHOG 